\title{
Avaliaçào de técnicas de rádio-rastreamento e marcação do peixe-boi da Amazônia, Trichechus inunguis (Mammalia: Sirenia)
}

\author{
Robin C. Best (') \\ G. Gene Montgomery $\left({ }^{2}\right)$ \\ Megumi Yamakoshi (')
}

\section{Resumo}

Os resultados de um estudo para avaliar técnicas de rádio-rastreamento e marcação por congelamento, aplicadas no estudo da ecologia de peixes-bois selvagens da Amazônia, são aqui apresentados. Um Trichechus inunguis jovem, macho, foi rádio-marcado e solto numa série de lagos de igapós, próximas de Manaus, Brasil. Um transmissor de $150 \mathrm{mHz}$ foi utilizado, preso a uma cinta, ao redor do pedúnculo caudal desse animal e os movimentos diários foram monitorados por 20 dias, utilizando-se técnicas padrões de triangulação. Os movimentos diários do animal (cerca de $2,6 \mathrm{~km} / \mathrm{d}$ ) foram facilmente seguidos e em muitas ocasiōes conseguiu-se chegar a uma distância de $3 \mathrm{~m}$ dele, sendo que observações de seu comportamento e alimentação foram feitas, tanto visualmente, como através do uso de um hidrofone. Baseadas nas respectivas taxas de movimento, não houveram diferenças significativas nos padrões de atividades diurna e noturna (dia: 0,14 $\pm 0,17$ $\mathrm{km} / \mathrm{h}$ e noite: $0,08 \pm 0,12 \mathrm{~km} / \mathrm{h}$ ). Cinco meses antes de sua libertação, o animal foi marcado por congelamento, por 25-30 segundos, com um ferrete de cobre e utilizando-se nitrogênio líquido como congelante. Embora houvesse um pequeno dano no tecido cutâneo, a ferida cicatrizou rapidamente, permanecendo uma marca branca, legivel. A interpretação dos dados de rádio-rastreamento, em estudo adicionais, é aqui discutida.

\section{INTRODUÇÃO}

Como resultado da exploração intensiva, o peixe-boi da Amazônia é o único sirênio vivo considerado "em perigo de extinção" (IUCN Red Data Book, 1976). A espécie é endêmica a meios-ambientes de água doce da Bacia Amazônica Central e pode ser encontrada nos três tipos primários de água da região: branca, preta e clara (Sioli, 1956), ocorrendo em lagos, igapós e igarapés dos rios (Pereira, 1944). Esta espécie tem uma longa história de exploração como alimento e, durante o perío- do de 1935-1954 por seu couro, extremamente durável, que era usado em produtos industriais (Carvalho, 1967; Ferreira, 1903; Mendes, 1938; Pereira, 1944). Durante a intensa exploração comercial, no período de 1935-1954, um número estimado em 200.000 peles de peixes-bois foi exportado da Amazônia, resultando numa severa redução da estirpe. O peixe-boi é legalmente protegido no Brasil desde o ano de 1967.

O desenvolvimento de planos para proteger e aumentar a criação de peixes-bois da Amazônia é dificultado pela falta de informação sobre sua ecologia e história natural. É difícil encontrar e observar peixes-bois selvagens devido a sua natureza tímida e as águas geralmente opacas de seus habitats. A visibilidade nas águas do Amazonas e seus maiores afluentes é no máximo de $1-2 \mathrm{~m}$ e estudos inteiramente baseados em observações diretas, como realizados por Hartman (1971) e Reynolds (1977), com o peixe-boi do Caribe (T. manatus), na Flórida, não são praticáveis aqui. Trabalhos publicados sobre ecologia e história natural do peixe-boi da Amazônia são baseados em informações fornecidas pela população local da região (Ferreira, 1903; Pereira, 1944; Rego, 1944; Veríssimo, 1895). Não há nenhum trabalho de observaçōes de primeira-mão, detalhadas, sobre $T$. inunguis em seu meio ambiente natural.

O rádio-rastreamento representa o único meio, atualmente disponivel, para um acompanhamento contínuo dos movimentos diários e sazonais de peixes-bois individuais. A utilização dessa técnica está muito avançada em estudos de ecologia de mamíferos terrestres e recentemente foi utilizada, com sucesso,

(1) - Instituto Nacional de Pesquisas da Amazônia, Manaus.

(2) - Smithsonian Tropical Research Institute, Balboa, Panamá. 
em mamíferos marinhos, como os golfinhos (Evans, 1971; 1974; Wuersig, 1976). Se o sinal de rádio for perdido, geralmente não é possível recapturar imediatamente o animal. Contudo, ele ainda pode ser recapturado ou morto numa data posterior e informações valiosas podem ainda ser obtidas se ele for individualmente reconhecido. Marcação por congelamento tem sido usada para marcar golfinhos individualmente (Evans et al., 1972).

Este trabalho apresenta e avalia técnicas de rádio-marcação e também marcação por congelamento que desenvolvemos, como precursores, para estudos ecológicos de longo prazo sobre peixes-bois da Amazônia. A biologia deste estudo já foi publicada, em parte, por Montgomery et al., (1981).

\section{Materiais e MÉtodos}

\section{ÁREA DE ESTUDO}

A área escolhida para o rádio-rastreamento é um habitat típico do peixe-boi. Consiste de três lagos de várzea ou planície inundada, na margem sul do rio Solimões $\left(60^{\circ} 20^{\circ} \mathrm{W}, 3^{\circ}\right.$ 30 'S). Esses lagos fazem parte do sistema de lagos de Janauacá. A área está sujeita à inundações sazonais, com o maior nível da água em junho e o menor em outubro (Schmidt, 1973). A amplitude anual da flutuação da água é de 10-15 m. Durante a cheia, a área é inundada com água "branca", rica em nutrientes do rio Solimões, resultando em grandes mudanças na transparência, condutibilidade, $\mathrm{pH}$. suspensões sólidas e nutrientes (Schmidt, 1973). Com a queda anual do nível do rio. o lago de várzea, mais uma vez, torna-se um sistema fechado e como os nutrientes estăo incorporados na sua biomassa e as suspensões sólidas precipitam, a água retorna à fase de água "preta".

A vegetação está altamente adaptada ao regime de inundação sazonal e é bastante diversa. Muitas espécies de plantas têm formas aquáticas e semi-aquáticas, ao passo que outras permanecem dormentes ou não produtivas durante a estação seca, tornando-se altamente produtivas somente quando estão inun- dadas (Junk, 1970). Das 36 espécies de plantas aquáticas e semi-aquáticas normalmente encontradas na área de estudo (Tabela 1), a maior diversidade, $25 \%$, estava representada pelos capins (Gramineae=Poaceae). De importáncia particular ao peixe-boi são aquelas planntas que formam uma parte dos capinzais flutuantes que se desenvolvem quando o nivel da água aumenta e os lagos se expandem (Fig. 1). Esses capinzais eventualmente formam uma densa massa de vegetação sobre tudo, exceto nas porções centrais e profundas dos lagos permanentes e fornece um diverso e rico potencial de fonte de alimento para peixes-bois .

\section{O ANIMAL EXPERIMENTAL}

$\mathrm{O}$ animal experimental era um macho jovem, com 1,66 m de comprimento e $108 \mathrm{~kg}$. Ele foi capturado por um pescador local, próximo a Autazes, na margem sul do rio Amazonas, no início de julho de 1976 e mantido em cativeiro, no INPA, por 20 meses depois de ser adquirido de seu proprietário original. $\mathrm{Na}$ época de sua libertação, sua idade estimada era cerca de 2-3 anos, baseada na taxa de crescimento de animais em cativeiro $\mathrm{ccm}$ idade conhecida e no estado da substituição dental (Domning \& Mager, 1978). Aparentemente o animal apresentava excelentes condições na época de sua libertação.

\section{MARCAÇÃO POR CONGELAMENTO}

O peixe-boi foi marcado por congelamento com os caracteres "INPA 13" no dia 01 de dezembro de 1977, utilizando-se um ferrete de cobre e nitrogênio líquido como congelante. Cada carácter media $4 \mathrm{~cm} \times 2 \mathrm{~cm}$ por $0.6 \mathrm{~cm}$ de largura. Uma marca clara foi obtida com um contato de 25-30 segundos (Fig. 2). Isso resultou em profundas lesões na pele mas a ferida não infeccionou e em 10 de janeiro de 1978 já estava completamente cicatrizada, deixando uma marca branca legivel. Na época da libertação a marca não mostrava nenhum sinal de deterioração. Um segundo animal, marcado por somente 15 segundos, mostrou danos superficiais no tecido, mas cerca de 5 meses depois a marca desapareceu completamente. 
TABELA 1 - Plantas aquáticas e semi-aquáticas coletadas na área durante o estudo. As plantas assinaladas por um asterisco são aquelas que se tem conhecimento de servirem de alimento ao peixe-boi na área.

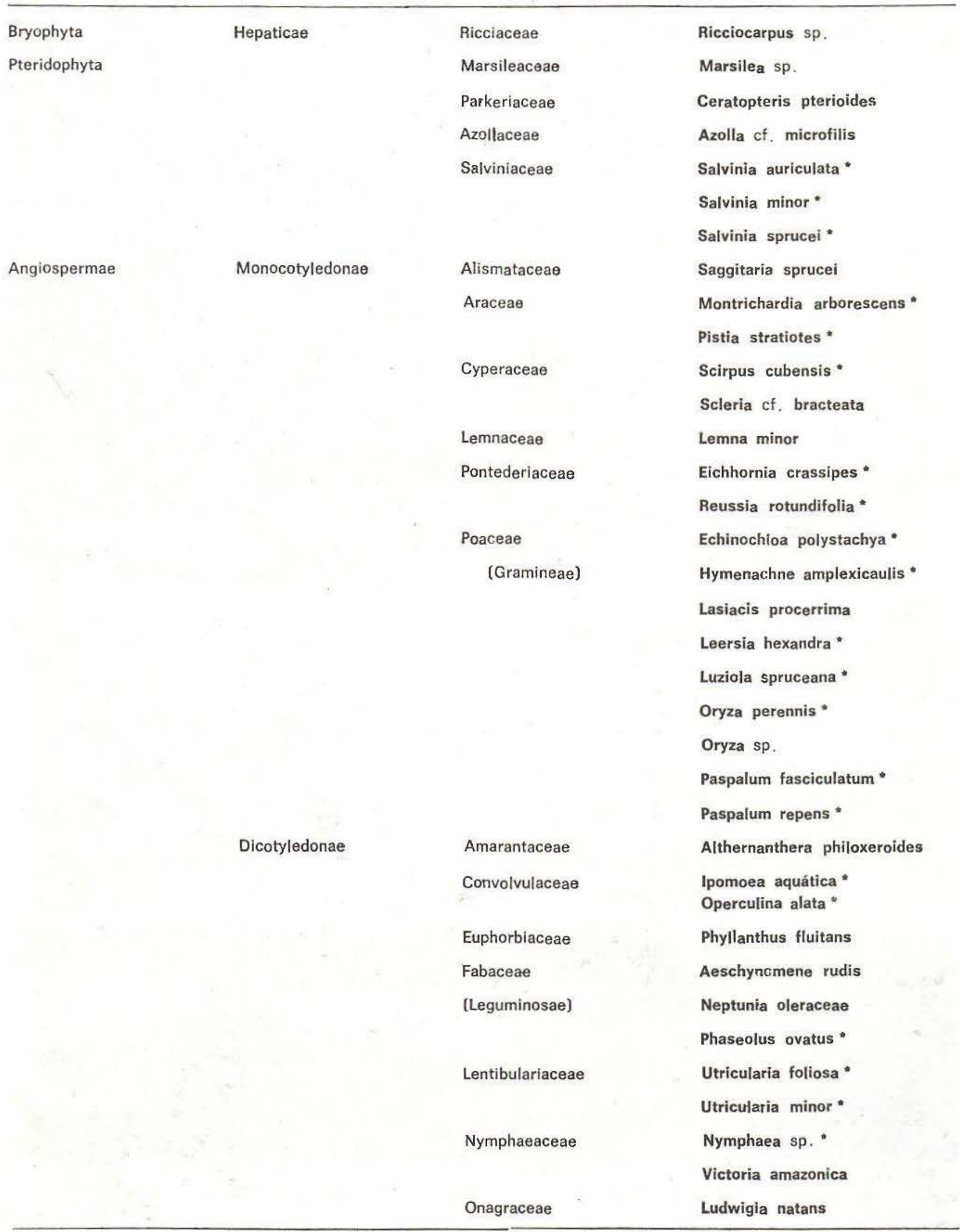


Embora a amostra seja pequena, os resultados indicam que a marcação por congelamento é segura, efetiva e aparentemente uma forma permanente de marcar peixes-bois .

\section{RÁDIO - TELEMETRIA}

Foi utilizado um rádio transmissor (modelo SM-2, AVM Instrument Co., Champaign, III.) que transmitia na faixa de $150 \mathrm{mHz}$. Essa freqüência foi usada por estar acima da sensibilidade auditiva do peixe-boi (cerca de $3 \mathrm{kHz}$ ) (Bullock et al., 1980) e evita o problema do anima! ouvir o sinal (Terhune, 1976). Os sinais eram monitorados por um receptor modelo LA 12 (AVM Instrument Co.) ou modelo Cedar Creek (Bioeletronics Laboratory, Bethel. Minn.) ligada a uma antena de 3 elementos, tipo "Yagi", montada num mastro de 4,8 metros.

0 transmissor e baterias foram encobertos por acrílico dental "Perm" e montados numa cinta de duas camadas, feita de correia de máquina, de $2,5 \mathrm{~cm}$ de largura. Uma antena de aço inoxidável trançado foi intercalada en- tre as duas camadas de correia de máquina, exceto por uma extensão de $15 \mathrm{~cm}$ que permaneceu de pé, na superfície dorsal (Fig. 3). O aparelho transmissor total pesava cerca de 200 gramas e foi colocado no pedúnculo caudal do animal, utilizando-se ferrolhos de aço inoxidável, de modo que o transmissor ficou montado na superfície ventral. O trarsmissor foi testado, quanto ao seu alcance, em água aberta, antes de ser colocado no animal. Ele foi colocado sob um flutuador a uma profundidade de 2 metros, usando-se, então, uma antena manual de 2 elementos, tipo "Yagi", obtendo-se um alcance de aproximadamente 2 $\mathrm{km}$ nas águas "brancas" do rio Solimōes e 5 km na água "preta" do rio Negro.

Após a instalação do rádio-transmissor, o peixe-boi foi mantido por uma noite num tanque, no laboratório e, então, transportado numa maca de lona, por caminhão (30 minutos), e num tanque de fibra de vidro de $2 \mathrm{~m} \times 2 \mathrm{~m} \times$ $1 \mathrm{~m}$, cheio de água, por barco (24 horas), ao lugar de sua libertação. O transmissor permaneceu no lugar durante todo esse tempo.

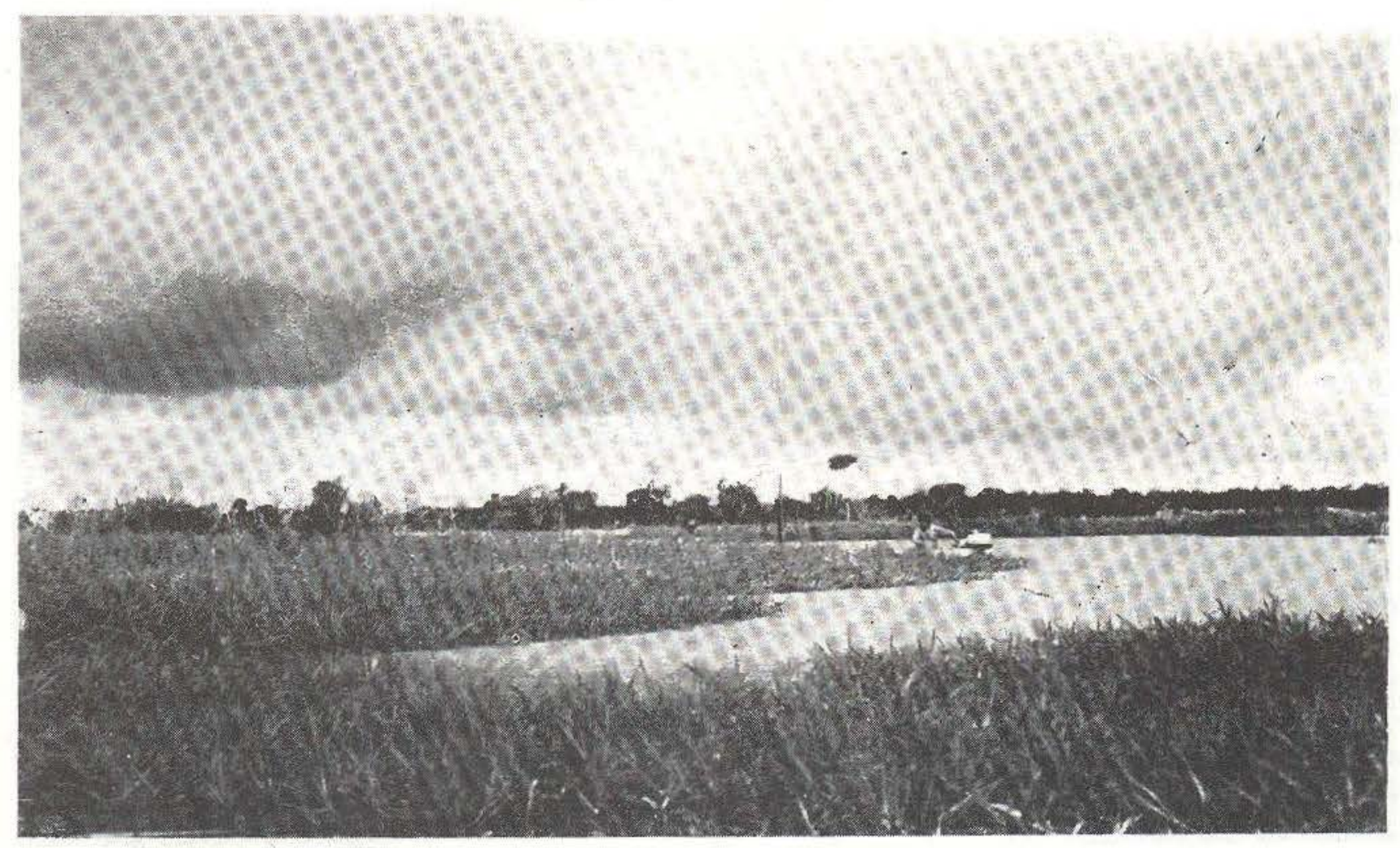

Fig. 1 - Os capinzais flutuantes da área de estudo, com a canoa e antena utilizadas para localizar o peixe-bol marcado. 

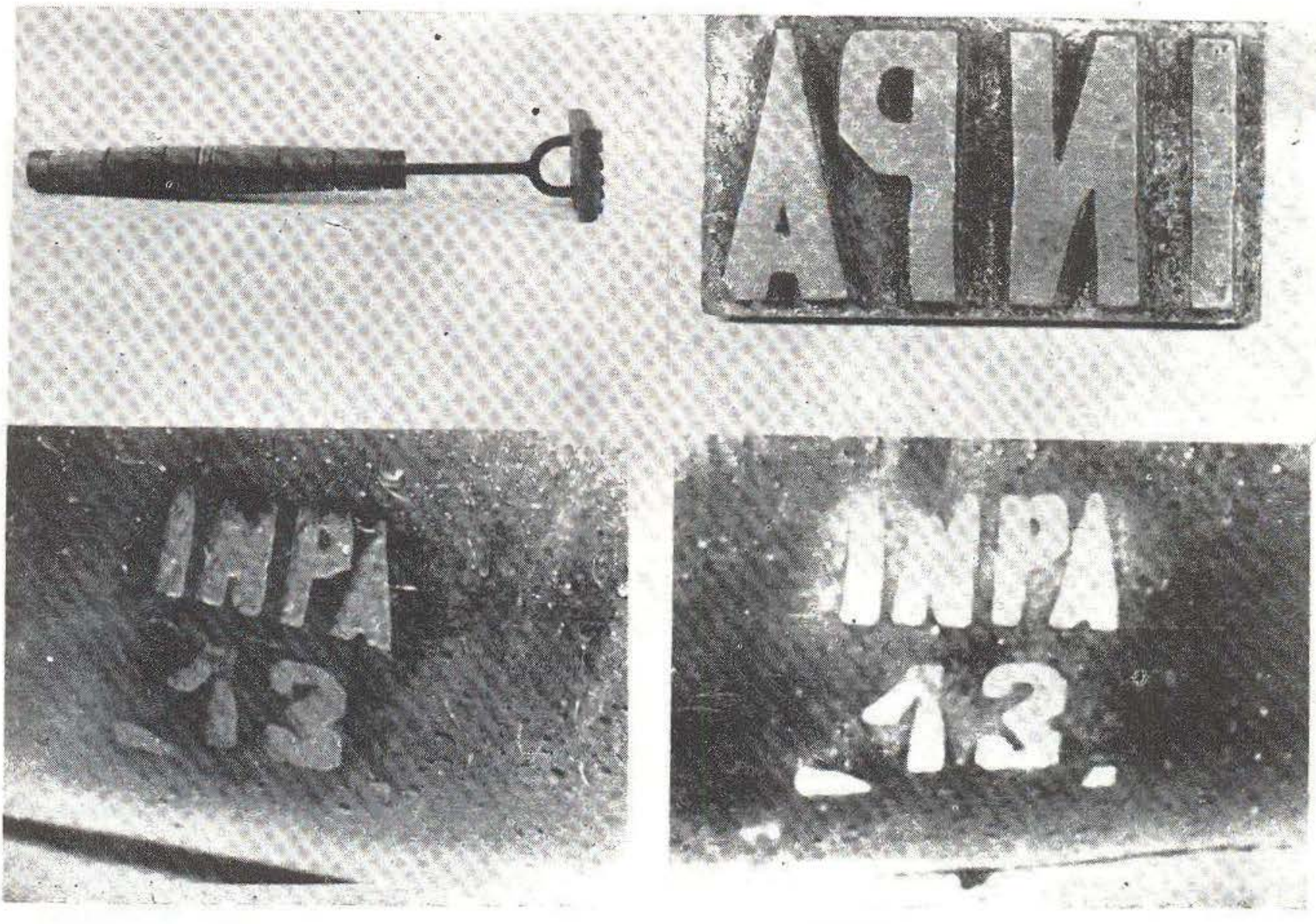

Fig. 2 - O ferrete de cobre usado para a marcação do peixe-boi, com nitrogênio líquido e a marca no dia em que foi feita e 40 dias depois.

Na tarde de 7 de abril de 1978, o peixe-boi foi solto no lago Boiaçu, no sistema do lago Janauacá, e um rádio-rastreamento intensivo foi iniciado. A fim de monitorar sua posição por triangulação, bóias foram colocadas em pontos de referência estratégicos. A direção do animal era determinada pela leitura de uma bússola orientada na direção de maior intensidade do sinal a partir de cada bóia, e sua posição era obtida pela intersecção de duas ou três de tais orientaçōes. As posições eram traçadas num mapa de $1: 100.000$, preparado através de fotografias aéreas e levantamento terrestre. A Fig. 4 mostra um diagrama escalado desse mapa.

As cinco maiores fontes de erro neste estudo foram:
(i) leitura da intensidade do sinal
(ii) leitura da bússola

(iii) bóias mal colocadas em relação ao animal

(iv) erros no mapeamento

(v) tempo de viagem entre as bóias

Embora seja possível reduzir alguns desses erros, em estudos futuros, não será possível eliminá-los inteiramente, sob condições de campo (cf. Heezen \& Tester, 1967, para discussões adicionais). Achou-se aconselhável tomar três orientações para cada localização, uma vez que isso obviamente permitiria identificar erros de leitura. Das 109 localizações efetuadas durante os 20 dias de estudo, 95 puderam ser utilizadas com confiança.

\section{INTERPRETAÇÃO DOS RESULTADOS}

Embora este estudo não pretendesse responder nenhuma questão biológica, ele indicou como tais problemas podem ser melhor 


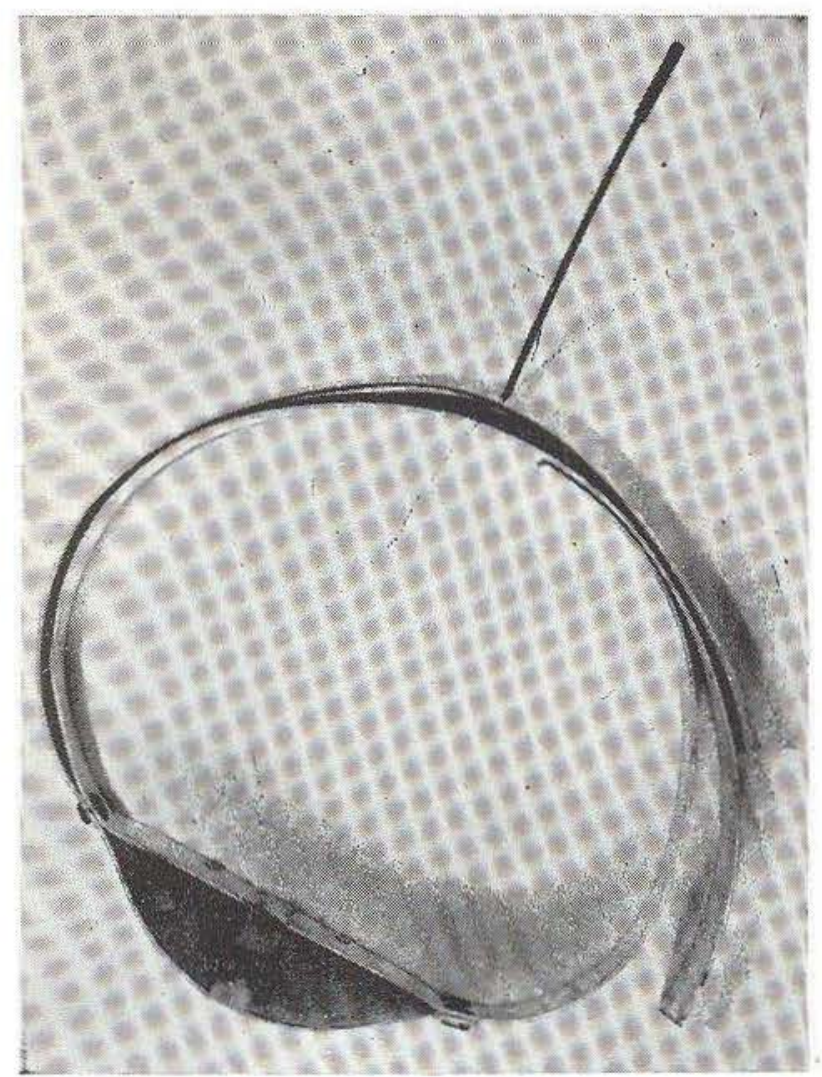

Fig. $3-\mathrm{O}$ transmissor foi colocado no pedúnculo caudal do peixe-boi e preso com ferrolhos de aço inoxidável, de modo que a antena ficou na superfície dorsal do animal.

abordados. Em nossos estudos mais amplos com rádio-rastreamento, esperamos ser capazes de obter informaçōes nos seguintes aspectos da biologia do peixe-boi:

(i) padrões de atividade

(ii) movimento de curto e longo prazo

(iii) seleção e utilização de habitat

(iv) comportamento

No presente estudo, taxas de deslocamento foram utilizadas como indice de atividade. Taxas de deslocamento não diferiram significativamente entre dia e noite: $\bar{x}$ dia $=0,14 ; S_{\text {dia }}=0,17 ; n_{\text {dia }}=48 ; \bar{x}_{\text {noite }}$ $=0,08 ; S_{\text {noite }}=0,12 ; \mathrm{n}_{\text {noite }}=47$. Isso concorda com os padrões de atividade desse animal quando em cativeiro (Best et al., não publicado) e também com observações do pejxe-boi do Caribe (Hartman, 1971; Reynolds, 1977). Um estudo mais detalhado permitiria a determinação de padrões de atividade circadianos mais sutís, se presentes nesta espécie.

A interpretação dos movimentos deste animal provavelmente tem pouco significado biológico, uma vez que ele foi mantido em cativeiro e foi solto numa área não familiar. Contudo, indica que o rastreamento detalhado de um peixe-boi é relativamente fácil e é muito pouco provável que taxas de movimento como o apresentado. $(\sim 2,6 \mathrm{~km} / \mathrm{d})$ dificultem um rastreamento contínuo. Estamos certos de que num estudo a longo prazo será possivel identificar parâmetros como delimitação de habitat e migraçōes sazonais.

$O$ animal deste estudo passou a maior parte do seu tempo nos capinzais flutuantes, particularmente onde margeavam o igapó (Fig. 1). Aparentemente ele evitou áreas de água aberta. Devido à resolução relativamente grande da técnica de triangulação, não é possível extrair informaçōes adicionais sobre uso de habitat e comportamento, por métodos remotos somente. Contudo, descobrimios durante o estudo que, uma vez determinada a localização aproximada podiamos nos aproximar do animal, numa canoa de madeira, usando uma pequena antena manual para determinar a posição exata. Desse modo pudemos fazer observações visuais de comportamento em geral e, de alimentação, a uma distância de 3-4 metros, sem perturbá-lo. Os sons distintos da mastigação da alimentaçăo do pejxe-boi foram facilmente captados por um hidrofone nessa hora. A possibilidade de uma aproximação do animal, uma vez que a posição seja conhecida, elimina a necessidade de refinamentos adicionais custusos, no sistema de localização remota.

Demonstramos que o rádio-rastreamento é uma solução prática (e talvez a única) para o estudo da ecologia do peixe-boi nas águas opacas, características da Bacia Amazônica. Tais técnicas são necessárias para conhecimentos adicionais sobre a espécie, que são críticos para a determinação de tamanhos mínimos de parques nacionais e reservas, nas quais o peixe-boi da Amazônia possa ser conservado. 


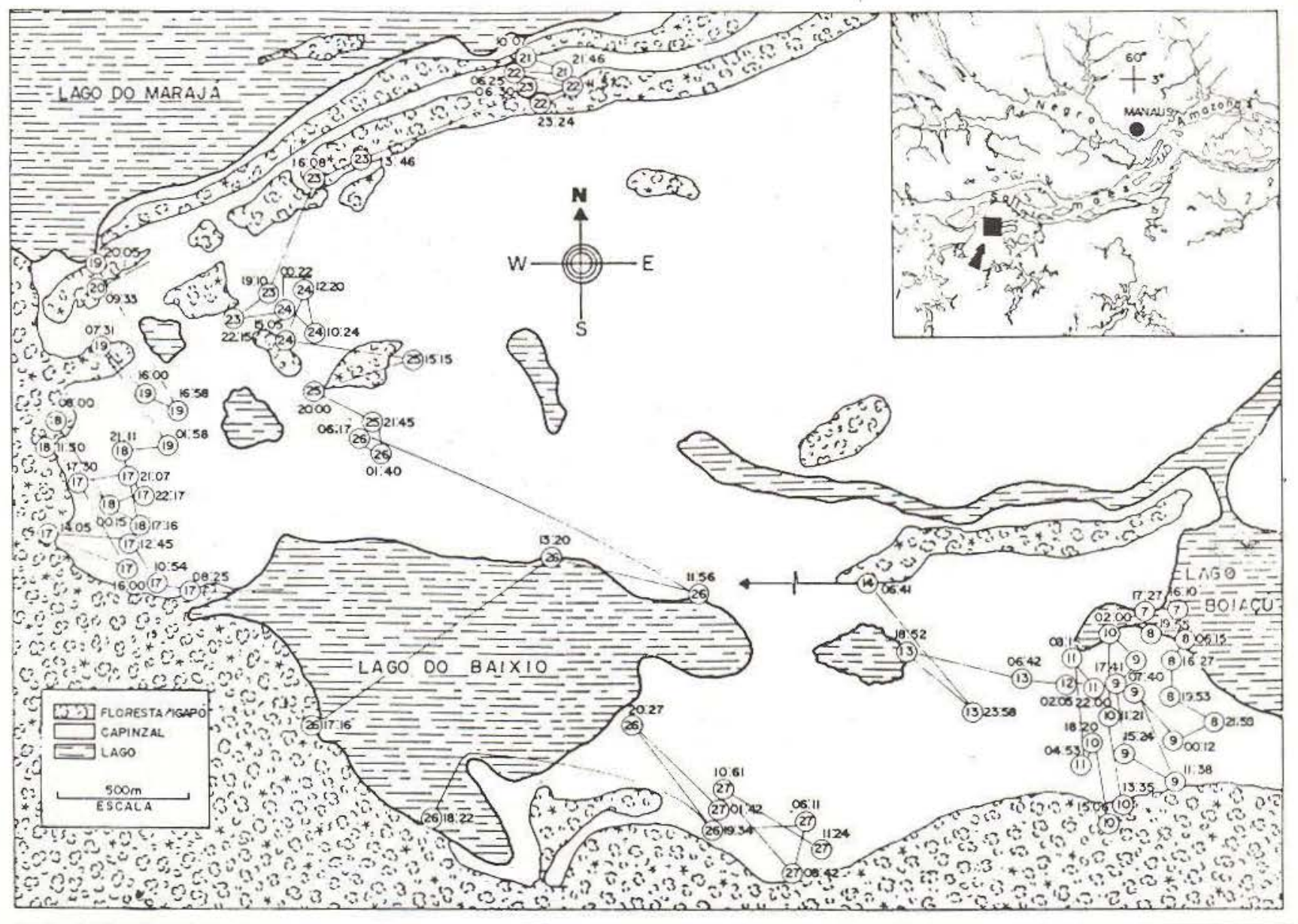

Fig. 4 - Localizações do peixe-boi n.o 13 durante os 20 dias de rádio-rastreamento. Os dias estão representados dentro dos círculos com as horas correspondentes ao lado. Os deslocamentos diários foram de aproximadamente 2.6 $\mathrm{km} / \mathrm{d}$ e não houve diferença entre as taxas de deslocamento diurno e noturno (segundo Montgomery et al., 1981).

\section{Agradectmentos}

O presente estudo é parte de um programa em andamento sobre a biologia e conservação do peixe-boi da Amazônia, desenvolvido pelo INPA. Esse programa é custeado pelo CNPq, INPA, com apoio adicional do IBDF, Vancouver Public Aquarium, Fauna Preservation Society (U.K.), World Wildlife Fund (U.S.), Smithsonian Institution's International Environmental Sciences Program e Smithsonian Tropical Research Institute. Agradecemos às seguintes pessoas, pela sua assistência durante o estudo: J. Waage, J. Gallivan, L. Branch, J.P. Poupard e a tripulação dos barcos de pesquisas PIUM e MARUPIARA, e W.E. Magnusson, J.M. Ayres e V.M.F. da Silva por seus comentários construtivos ao manuscrito. Agradecemos ainda o generoso apoio logístico e permissão para a execução deste trabalho, oferecido por W. Junk, W.E. Kerr e Maria Teresa J. Pádua.

\section{SUMMARY}

The results of a study to evaluate radio-tracking and freeze-branding techniques as applied to the study of the ecology of wild Amazonian manatees are presented. A young male Trichechus inunguis was radio-marked and released in a series of flood-plain lakes near Manaus, Brasil. We used a $150 \mathrm{mHz}$ trans. mitter attached by a "coliar" around the caudal peduncle of this animal and the daily movements were monitored during 20 days using standard triangulation techniques. We were easily able to follow the animal's movements $(\simeq 2.6 \mathrm{~km} / \mathrm{d})$ and on several occasions were able to approach to within $3 \mathrm{~m}$ of it and make behavioural and feeding observations both visually and using a hydrophone. Based on the respective rates of movement there were no significant differences between day and night activity patterns (day, $0.14 \pm 0.17$ 
$\mathrm{km} / \mathrm{h}$ and night $0.08 \pm 0.12 \mathrm{~kg} / \mathrm{h}$ ). Five months prior to its release the animal was freeze-branded for 25-30 sec. with a copper branding iron using liquid nitrogen as the coolant. Although there was some cutaneous tissue damage, the brand healed quickly and a legible mark remained. The interpretation of radio-tracking dacia in further studies is discussed.

\section{REFERENCIAS BIBLIOGRAFICAS}

BULLOCK, T.H.; DOMNING, D.P.; BEST, R.C

1980 - Evoked brain potentials demonstrate hearing in a manatee (Sirenia: Trichechus inunguis). J. Mammal., 61(1): 130-133.

CARVALHO, J.C. de M.

1967 - A conservação da natureza e recursos naturais na Amazôria Brasileira. Atas Simp. Biota Amazônica, $7: 71-74$.

DOMNING, D.P. \& MAGOR, D.M.

1978 - Taxa de substituição horizontal de dentes no peixe-boi. Acta Amazonica, $7: 435-438$.

EVANS, W.E.

1971 - Orientation behaviour of delphinids: radio telemetric studies Ann. N. Y. Acad. Sci., $188: 142-160$

1974 - Radio telemetric studies of two species of small odontocete cetaceans. In: The Whale Problem: A Status Report, editada por W. Schevill, Harvard Univ. Press : 386-394.

EVANS, W.E.; HALL, J.D.; IRVINE, A.B.:

LEATHERWOOD, J. S.

1972 - Methods for tagging small cetaceans. Fish. Bull., 70(1) : 61-65.

FERREIRA, A.R.

1903 - Memória sobre o peixe-boi e do uso que the dão no estado do Grão Pará. Arq. Museu Nacional (Rio c'e Janeiro), $12: 169-174$.

HARTMAN, D.S

1971 - Behaviour and ecology of the Florida manatee, Trichechus manatus latirostris (Harian), at Crystal River, Citrus County. Dissertação para tese de Ph.D.. Cornell Univ., 285 p.

HEEZEN, K.L. \& TESTER, J.R.

1967 - Evaluation of radio-tracking by triangulation with special reference to deer movements. J. WildI. Manage, 31(1): $124-141$.

I.U.C.N

1976 - Trichechus inunguis. Red Data Book. Vol I. International Union Conservation of Nature, Morges, Suiça.
JUNK, W.J

1970 - Investigations on the ecology and production biology of the "floating meadows" (Paspalo - Echinochloetum) on the Middle Amazon: I. The floating vegetation and its ecology. Amazoniana, 2 : 449-495.

MENDES, A.

1938 - As pescarias amazônicas e a piscicultura no Brasil (Notas e Sugestōes), Livraria Editora Record, São Paulo, $181 \mathrm{p}$.

MONTGOMERY, G.G.; BEST, R.C. \& YAMAKOSHI, M.

1981 - A radio-tracking study of the Amazonian manatee Trichechus inunguis (Mammalia: Sirenia). Biotropica (No prelo).

PEREIRA, M.N.

1944 - O peixe-boi da Amazônia. Boll. Minist. Agric. (Rio de Janeiro), 33(5): 21-95

REYNOLDS, J.E.

1977 - Aspects of the social behaviour and ecology of a semi-isolated colony of Florida manatees Trichechus manatus. Não publicado. Tese de M.Sc., Univ. Miami, Coral Gables, Florida, 206 p.

REGO, A.R. de M.

1944 - O peixe-boi. Rev. Mus. Nacional (Rio de Janeiro), 2:10-12

SCHMIDT, G.W.

1973 - Primary production of phytoplankton in the three types of Amazonian waters. II. The limnology of a tropical food-plain lake in Central Amazonia (lago do Castanho). Amazoniana, 4(2): 139-203.

SIOLI, H.

1956 - Uber Natur und Mersch im brası!ianischen Amazonasgebiet. Erdkunde, 10(2): 89-109.

TERHUNE, J.M.

1976 - Audibility aspects of sonic trackirig of marine animals. J. Mammal., 57(1):179-180.

VERISSIMO, J

1895 - A pesca na Amazônia. Livraria Clássica de Alves e Cia., Filo de Janeiro. 127 pp. (Reimpresso em 1970 pela Univ, do Pará).

WUERSIG, $B$

1976 - Radio tracking of dusky porpoises (Lagenorhynchus obscurus) in the South Atlantic: A preliminary study. Scientific Consultation on Marine Mammals, Bergen, Norway ACMER/MM/SC83 : 1-21.

(Aceito para publicação em $6 / 3 / 81$ ) 